\title{
Gender differences in the surgical management of lumbar degenerative disease: a scoping review
}

\author{
Mark A. MacLean, MD, MSc, ${ }^{1}$ Charles J. Touchette, MD, ${ }^{2}$ Jae H. Han, MD, ${ }^{1}$ \\ Sean D. Christie, MD, FRCSC, ${ }^{1}$ and Gwynedd E. Pickett, MD, FRCSC ${ }^{1}$
}

${ }^{1}$ Division of Neurosurgery, Dalhousie University QEIl Health Sciences Centre, Nova Scotia Health Authority, Halifax, Nova Scotia, Canada; and 'Division of Neurosurgery, Universitaire de Sherbrooke, Centre de recherche du Centre Hospitalier, Sherbrooke, Quebec, Canada

OBJECTIVE Despite efforts toward achieving gender equality in clinical trial enrollment, females are often underrepresented, and gender-specific data analysis is often unavailable. Identifying and reducing gender bias in medical decisionmaking and outcome reporting may facilitate equitable healthcare delivery. Gender disparity in the utilization of surgical therapy has been exemplified in the orthopedic literature through studies of total joint arthroplasty. A paucity of literature is available to guide the management of lumbar degenerative disease, which stratifies on the basis of demographic factors. The objective of this study was to systematically map and synthesize the adult surgical literature regarding gender differences in pre- and postoperative patient-reported clinical assessment scores for patients with lumbar degenerative disease (disc degeneration, disc herniation, spondylolisthesis, and spinal canal stenosis).

METHODS A systematic scoping review was performed according to the Preferred Reporting Items for Systematic Reviews and Meta-Analyses Extension for Scoping Reviews (PRISMA-ScR) guidelines. MEDLINE, Embase, and the Cochrane Registry of Controlled Trials were searched from inception to September 2018. Study characteristics including patient demographics, diagnoses, procedures, and pre- and postoperative clinical assessment scores (pain, disability, and health-related quality of life [HRQoL]) were collected.

RESULTS Thirty articles were identified, accounting for 32,951 patients. Six studies accounted for $84 \%$ of patients; 5 of the 6 studies were published by European groups. The most common lumbar degenerative conditions were disc herniation (59.0\%), disc degeneration (20.3\%), and spinal canal stenosis (15.9\%). The majority of studies reported worse preoperative pain (93.3\%), disability (81.3\%), and HRQoL (75\%) among females. The remainder reported equivalent preoperative scores between males and females. The majority of studies $(63.3 \%)$ did not report preoperative duration of symptoms, and this represents a limitation of the data. Eighty percent of studies found that females had worse absolute postoperative scores in at least one outcome category (pain, disability, or HRQoL). The remainder reported equivalent absolute postoperative scores between males and females. Seventy-three percent of studies reported either an equivalent or greater interval change for females.

CONCLUSIONS Female patients undergoing surgery for lumbar degenerative disease (disc degeneration, disc herniation, spondylolisthesis, and spinal canal stenosis) have worse absolute preoperative pain, disability, and HRQoL. Following surgery, females have worse absolute pain, disability, and HRQoL, but demonstrate an equal or greater interval change compared to males. Further studies should examine gender differences in preoperative workup and clinical course.

https://thejns.org/doi/abs/10.3171/2019.11.SPINE19896

KEYWORDS gender; disparity; differences; sex; spine; lumbar; degenerative; stenosis; spondylolisthesis; disc degeneration; patient-reported outcome

\footnotetext{
ABBREVIATIONS DSL = degenerative spondylolisthesis; EQ-5D = EuroQol-5D; HRQoL = health-related quality of life; $L D H=$ lumbar disc herniation; $M C I D=$ minimal clinically important difference; MSC = modified Stauffer-Coventry; NRS = numeric rating scale; OA = osteoarthritis; ODI = Oswestry Disability Index; OFI = Objective Functional Impairment; PRISMA-ScR = Preferred Reporting Items for Systematic Reviews and Meta-Analyses Extension for Scoping Reviews; QST = quantitative sensory testing; RCT = randomized controlled trial; RDQ = Roland-Morris Disability Questionnaire; SF-12 = Short-Form 12; SF-36 = Short-Form 36; SIP-PD = Sickness-Impact-Profile Physical Dimension; SPORT = Spine Outcomes Research Trial; TJA = total joint arthroplasty; TUG = Timed-Up-and-Go; VAS = visual analog scale.

SUBMITTED July 31, 2019. ACCEPTED November 25, 2019.
}

INCLUDE WHEN CITING Published online January 31, 2020; DOI: 10.3171/2019.11.SPINE19896. 
$\mathrm{P}$ ATIENT preference is an integral component of shared medical decision-making. ${ }^{28}$ Preference-based care provides patients with the autonomy to understand and appreciate relevant information, weigh treatment options, and make informed decisions. ${ }^{24}$ Despite the apparent utility of this model, many studies consistently document racial, ethnic, and gender disparities in the use of health services (we refer to gender as the socially acquired aspect of being male or female). ${ }^{35}$ White males are frequently reported to receive better access to medical and surgical interventions compared to females and minorities. ${ }^{3,9,13,18,25,31,46}$ Despite efforts toward gender equality in clinical trial enrollment, females are often underrepresented and gender-specific data analysis is often unavailable. . $38^{38}$

Gender disparity in the utilization of surgical therapy has been exemplified in the orthopedic literature by studies of total joint arthroplasty (TJA).$^{38}$ It has been reported that female patients are offered surgery later in the course of their disease, and have worse preoperative pain, disability, and radiographic findings. ${ }^{38}$ While empirical research demonstrates sex differences in clinical and experimental pain responses, ${ }^{15}$ clinical studies of TJA have demonstrated that following surgery, females experience similar improvement in pain and disability compared to males. . $^{11,36,42}$

Identifying and reducing gender bias in medical decision-making and outcome reporting may facilitate equitable healthcare delivery. A paucity of literature is available to guide the surgical management of lumbar degenerative disease that stratifies on the basis of demographic factors. ${ }^{17,22,64}$ Given these challenges, our objective was to map and synthesize the adult surgical literature regarding gender differences in pre- and postoperative patientreported clinical assessment scores for patients diagnosed with lumbar degenerative disease (disc degeneration, disc herniation, spondylolisthesis, and spinal canal stenosis).

\section{Methods \\ Study Design}

A scoping review was systematically conducted according to the Preferred Reporting Items for Systematic Reviews and Meta-Analyses Extension for Scoping Reviews (PRISMA-ScR) guidelines. ${ }^{55}$ This study design was utilized to map and synthesize the degenerative lumbar spine literature dichotomizing patient-reported clinical assessment scores by gender.

\section{Research Question}

Do adult female patients with a diagnosis of lumbar degenerative disease (disc degeneration, disc herniation, spondylolisthesis, and spinal canal stenosis) have worse absolute pre- and postoperative patient-reported clinical assessment scores (pain, disability, and health-related quality of life [HRQoL]) compared to males?

\section{Search and Inclusion/Exclusion Criteria}

A comprehensive electronic search of the literature was conducted with the assistance of a medical research librarian. MEDLINE, Embase, and the Cochrane Central Register of Controlled Trials were searched from incep- tion until September 2018. Search terms included subject headings (MeSH terms) specific to the respective databases (Supplemental Digital Content A). Free-text words relevant to gender, sex, and spinal surgery (discectomy, laminectomy, and/or instrumented fusion) for lumbar degenerative diseases (disc degeneration, disc herniation, spinal canal stenosis, and spondylolisthesis) were included. Abstracts were screened using predefined inclusion and exclusion criteria (Table 1). Eligible abstracts were imported into Covidence Review Manager. Duplicate articles were excluded automatically. A single reviewer (M.A.M.) reviewed exclusions to ensure accuracy of the duplicate removal algorithm. Two reviewers (M.A.M., J.H.H.) independently screened titles and abstracts using the criteria for inclusion. Full texts for citations passing the screening were then further assessed (M.A.M., C.J.T.) for eligibility. In cases of disagreement, consensus was reached via open discussion.

\section{Data Collection}

A standardized data extraction form was reviewed and refined by all authors prior to use (Supplemental Digital Content B). Study characteristics collected included article citation, database (if applicable), country of publication, study design, sample size, number and percentage of male and female patients in the cohort, diagnoses treated, corresponding surgical procedure, and study objectives (Table 2). Other variables included timing of assessments, assessment scoring measures, pre- and postoperative assessment scores, interval change in scores, and study conclusions (Table 3). Reference lists of all included full-text articles were manually searched (M.A.M.). Institution and database of published studies were used to avoid inclusion of duplicate patient data. When multiple papers were published utilizing the same cohort of patients, the largest sample with the greatest duration of follow-up was selected. Pre- and postoperative patient-reported clinical assessment results were categorized according to pain, disability, and HRQoL. Scoring measures for back and leg pain included the visual analog scale (VAS) and numeric rating scale (NRS); for disability, the Oswestry Disability Index (ODI), Roland-Morris Disability Questionnaire (RDQ), Sickness-Impact-Profile Physical Dimension (SIP-PD), and modified Stauffer-Coventry (MSC) score; and for HRQoL, the Short-Form 12 (SF-12), Short-Form 36 (SF-36), and EuroQol-5D (EQ-5D). Other scoring tools less commonly used are listed in Table 3 . A comparative analysis was not performed due to the heterogeneous nature of the collected data.

\section{Evidence Appraisal}

Included studies were critically appraised by two reviewers (M.A.M., C.J.T.) using the "Oxford Levels of Evidence 2" grading system. ${ }^{27}$ Disagreements were resolved through open, full-text review.

\section{Results}

\section{Literature Search and Selection}

Our initial database search yielded 1523 articles. After duplicates $(n=268)$ were removed, titles and abstracts 
TABLE 1. Inclusion and exclusion study criteria

\begin{tabular}{|c|c|}
\hline Inclusion Criteria & Exclusion Criteria \\
\hline - Original research on human subjects & - Cervical, thoracic, or sacral disease \\
\hline - Mean cohort age $\geq 18$ yrs & - Disease related to trauma, infection, \&/or neoplasm \\
\hline $\begin{array}{l}\text { - Diagnosed w/ lumbar degenerative disease; examples include } \\
\text { degenerative disc disease, disc herniation, spinal canal stenosis, \& } \\
\text { degenerative spondylolisthesis }\end{array}$ & - Case series \& case reports \\
\hline - Direct comparison of M \& F pts & - Publication language other than English \\
\hline $\begin{array}{l}\text { - Use of at least } 1 \text { pt-reported clinical assessment scoring tool: HRQoL } \\
\text { (SF-36 or EQ-5D), pain or anxiety (VAS, NRS, BRS), disability (ODI, } \\
\text { RDQ, SIP-PD, MSC score), global functional status (Beaujon scoring } \\
\text { system), satisfaction (Likert scale), or other (COMI, Barthel Index) }\end{array}$ & $\begin{array}{l}\text { - Studies not reporting statistical testing } \mathrm{w} / \text { significance values reported } \\
\text { as either } p \text { values or effect sizes } \mathrm{w} / 95 \% \mathrm{Cls}\end{array}$ \\
\hline \multicolumn{2}{|l|}{$\begin{array}{l}\text { - Contain a majority of pts } w / \text { at least } 1 \text { of the following assessment } \\
\text { dates: preop or postop (for those w/ only preop data, pts must have } \\
\text { been scheduled for or awaiting spinal surgery) }\end{array}$} \\
\hline - Prospective or retrospective cohort design & \\
\hline
\end{tabular}

BRS $=$ Borg Rating Scale; COMI = Core Outcomes Measure Index; $p t=$ patient.

( $\mathrm{n}=1255)$ underwent screening and 1219 articles were excluded. Full text was obtained for 36 studies to assess eligibility. Thirteen articles were excluded via full-text assessment. Twenty-three articles were included. 6,12,14,19,20, 23,26,29,32,34,37,39,41,47,48,50,52-54,56-58,63 The reference list of each included article was manually searched. An additional 7 articles were identified, 2,7,21,40,48,59,60 resulting in 30 articles for data collection. The PRISMA flow diagram summarizes the selection process (Fig. 1).

\section{Study and Cohort Characteristics}

Descriptive characteristics are presented in Table 2. The included studies contained a combined total of 32,951 patients. The total numbers of male and female patients were $16,651(50.5 \%)$ and $16,300(49.5 \%)$, respectively. On average, patients were operated on at the age of 51.2 years for males and 48.8 years for females. The majority of included studies reported no gender differences in BMI at the time of preoperative assessment. No study examined the association between gender and BMI in relation to clinical assessment scores. Furthermore, no study examined gender differences in sarcopenia or composite frailty measures. Data included in this review are mainly from European cohorts (70\%), followed by North American (16.7\%) and other continents (13.3\%). Prospective cohorts represent $30 \%$ of the data, whereas retrospective analysis of either prospectively $(60 \%)$ or retrospectively $(3.3 \%)$ collected data forms the rest. Two articles provide data from randomized cohorts, contributing 890 patients $(2.7 \%$ of the total). ${ }^{39,40}$ Six studies account for 27,754 patients (84.2\%); 5 were published by European groups. ${ }^{41,48,52-54,56}$

\section{Diagnoses and Procedures}

All patients were diagnosed with lumbar degenerative disease. Specific diagnoses (e.g., disc degeneration, disc herniation, spondylolisthesis, and spinal canal stenosis) were available for 32,567 patients (98.8\%). A single study included patients with multiple degenerative conditions without reporting the number of patients per diagnosis. ${ }^{14}$ Disc herniation (59.0\%), disc degeneration (20.3\%), spinal canal stenosis (15.9\%), and spondylolisthesis $(4.7 \%)$ accounted for the majority of diagnoses. The majority of studies contained a cohort of patients with the same diagnosis: disc herniation (26.7\%), spinal canal stenosis (26.7\%), disc degeneration (13.3\%), and spondylolisthesis $(6.7 \%)$. Seven studies $(23.3 \%)$ did not restrict inclusion criteria to a single diagnosis; all 7 presented clinical assessment scores dichotomized by gender but did not stratify by diagnosis. ${ }^{19,20,34,41,48,54,59}$ No study examined gender differences in the severity of radiographic findings.

A discectomy was performed in all cases of disc herniation and none conducted concomitant laminectomy with fusion. Of the 15 studies reporting postoperative scores for patients with spinal canal stenosis, $12(80.0 \%)$ reported laminectomy only. Laminectomy with instrumented fusion was mostly performed for spondylolisthesis or disc degeneration $(92.9 \%)$.

\section{Main Study Objectives and Patient-Reported Clinical Assessment Scales}

Examining gender differences in clinical assessment scoring was the primary objective in 17 studies $(56.7 \%)$. Scoring measures used in pre- and postoperative patientreported clinical assessment are listed in Table 3. The VAS score for back or leg pain was used by $94.7 \%$ of the studies reporting on pain. The ODI was used by $72.0 \%$ of the studies assessing disability. The EQ-5D (52.9\%) and SF-36 (41.2\%) were the most common measures of HRQoL. Gender differences were evaluated over a followup period averaging 27 months across included studies.

\section{Preoperative Pain, Disability, and HRQoL}

Of the studies reporting preoperative clinical assessment data (Table 3), all 18 (100\%) reported significant differences between male and female patients in at least one of the following categories: back or leg pain, disability, 


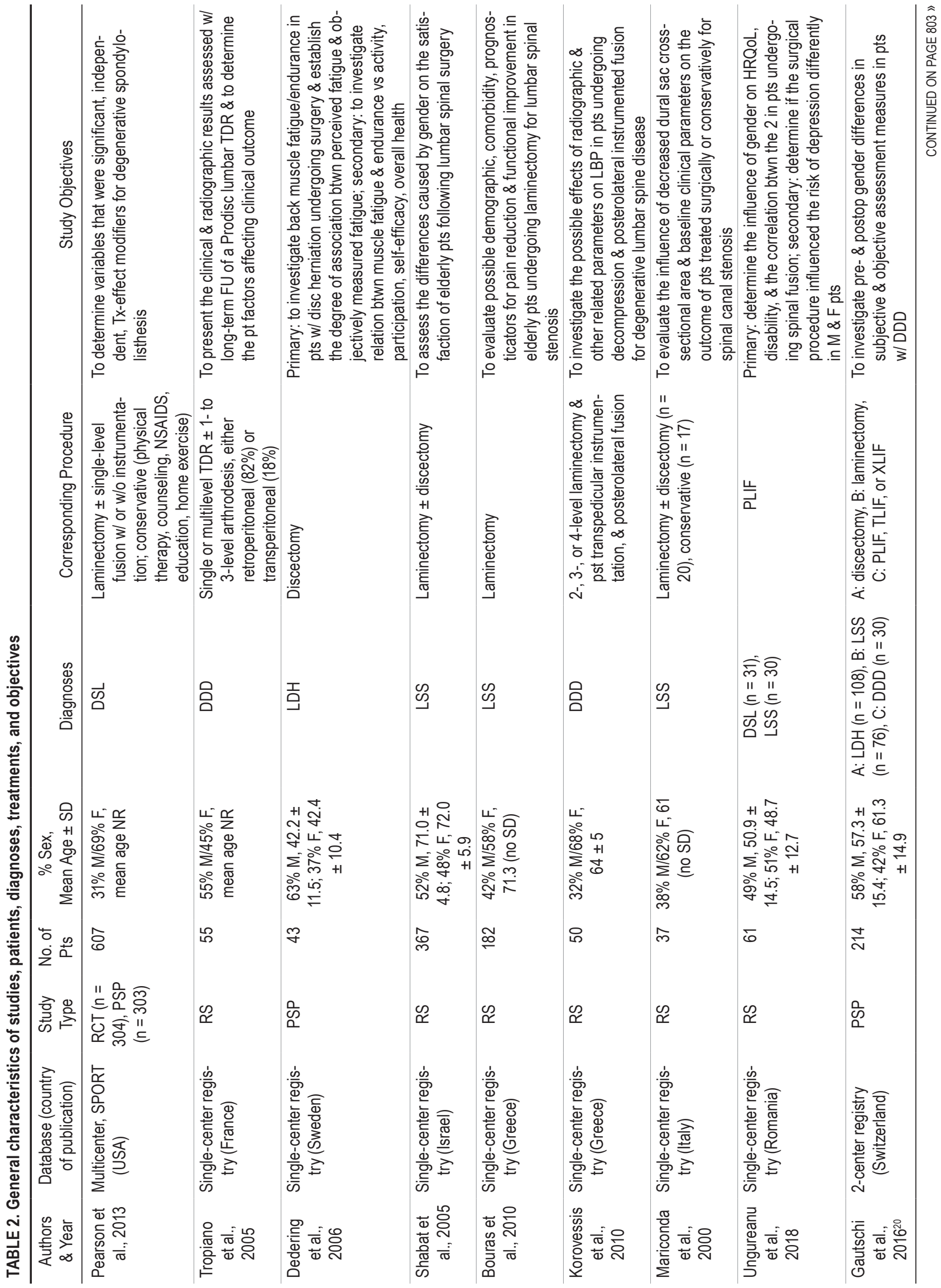




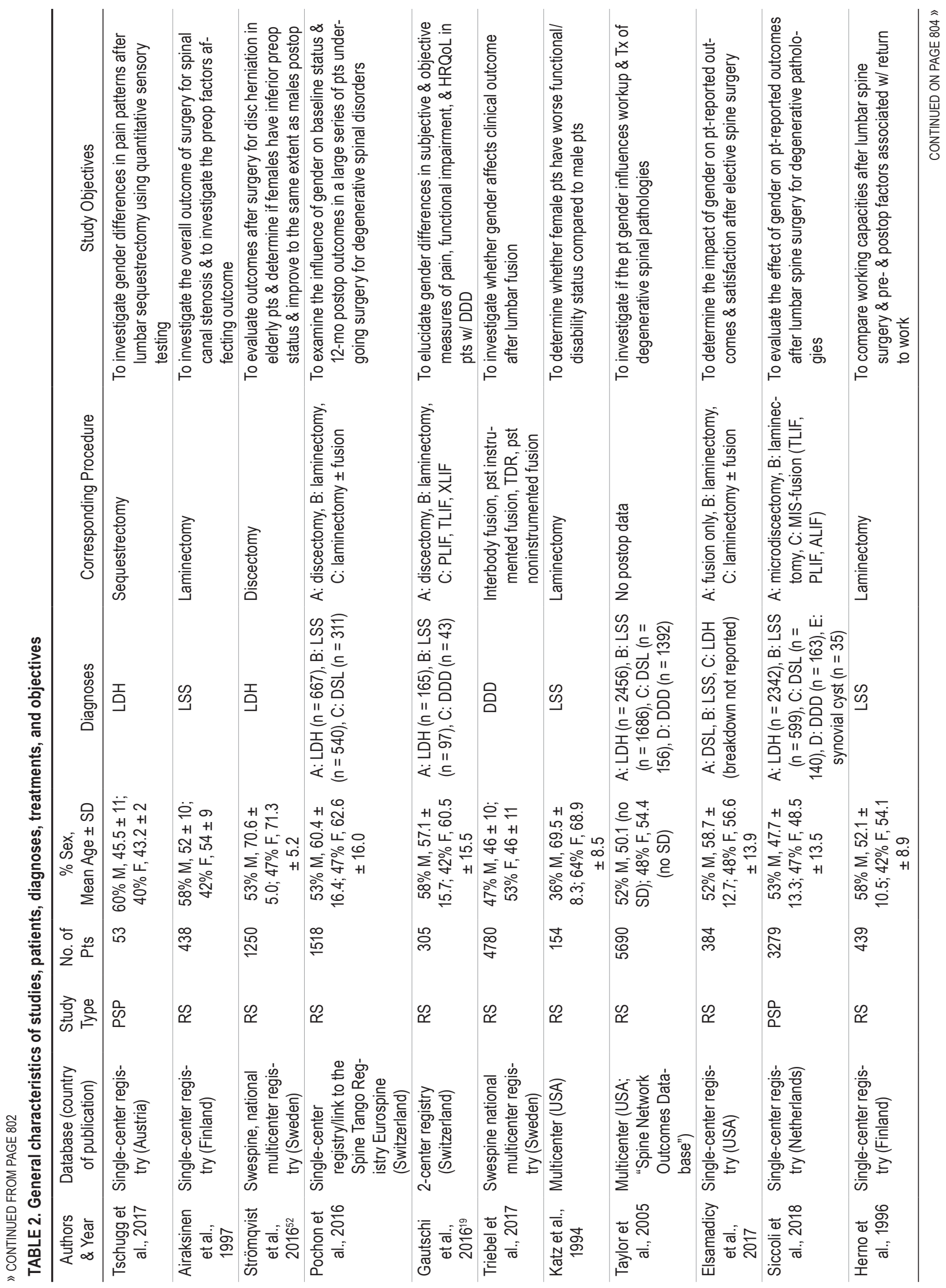




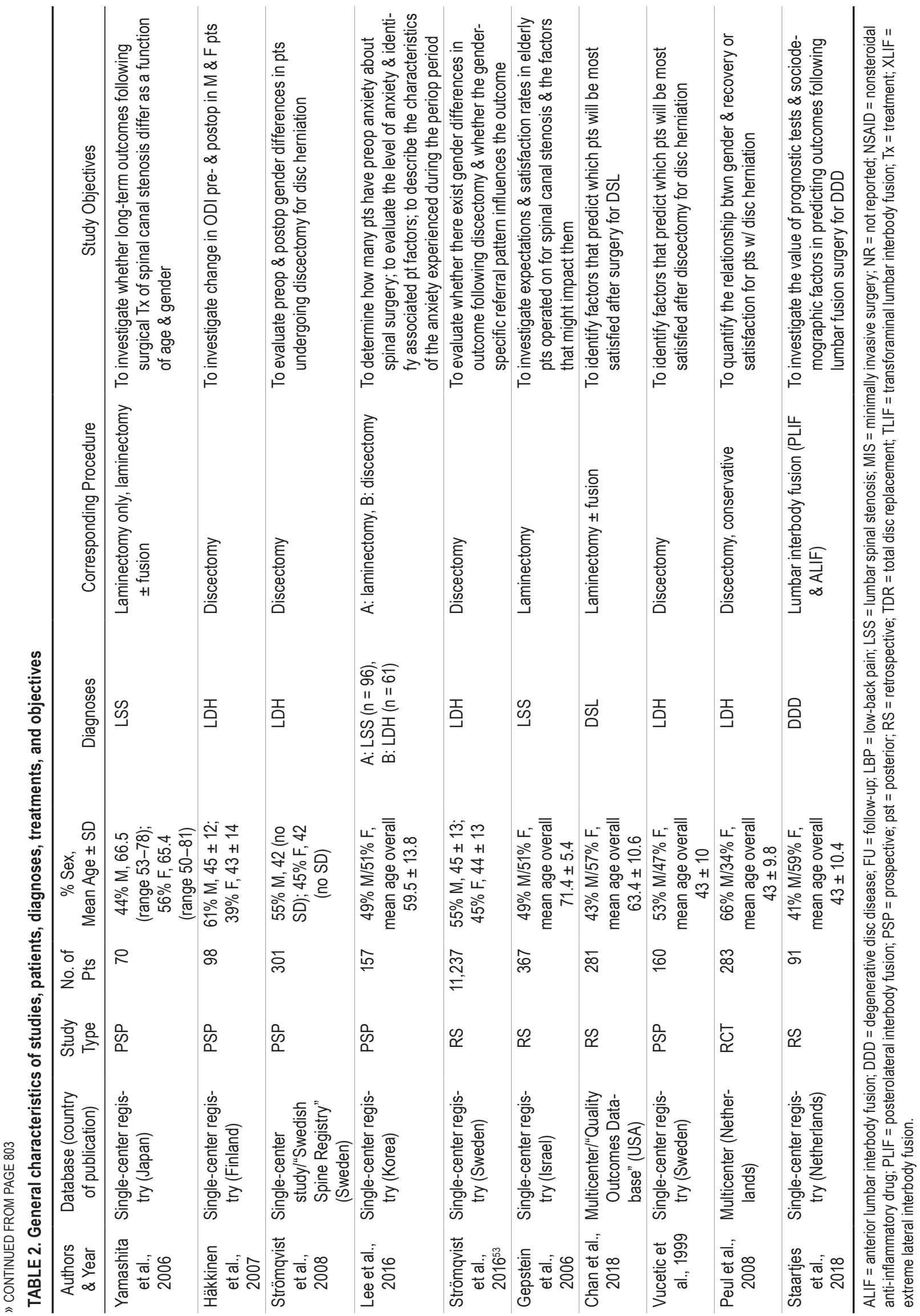




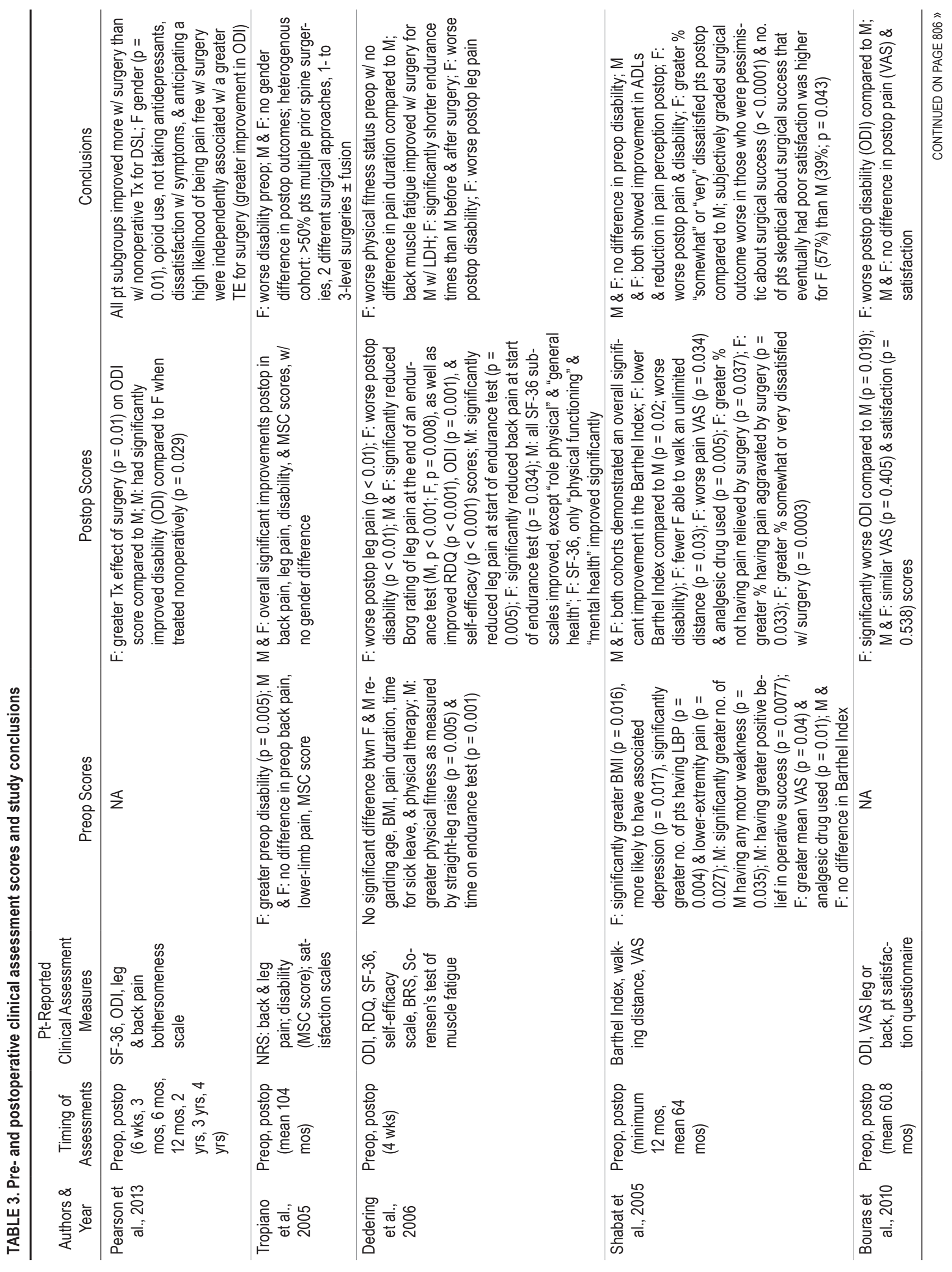




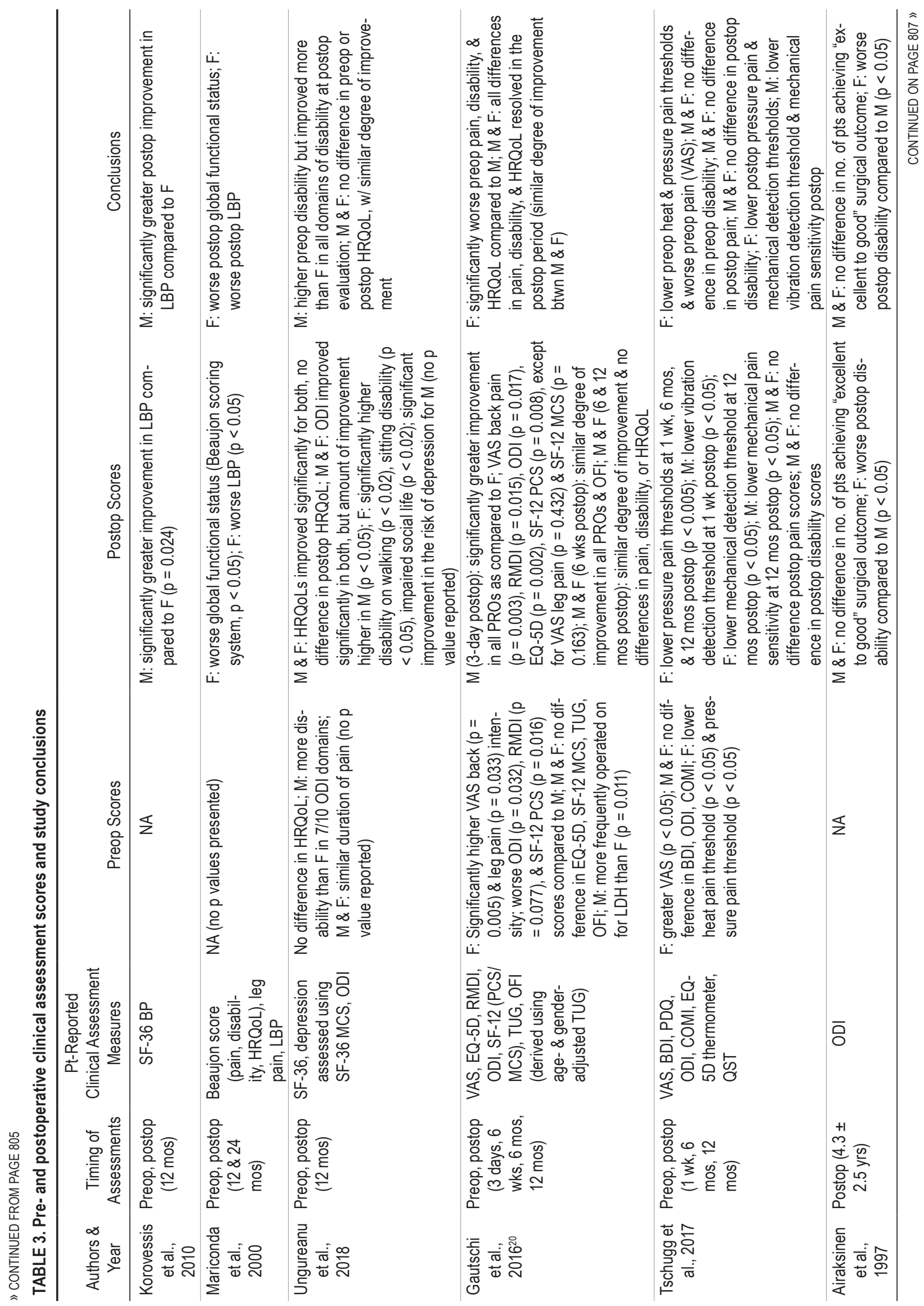




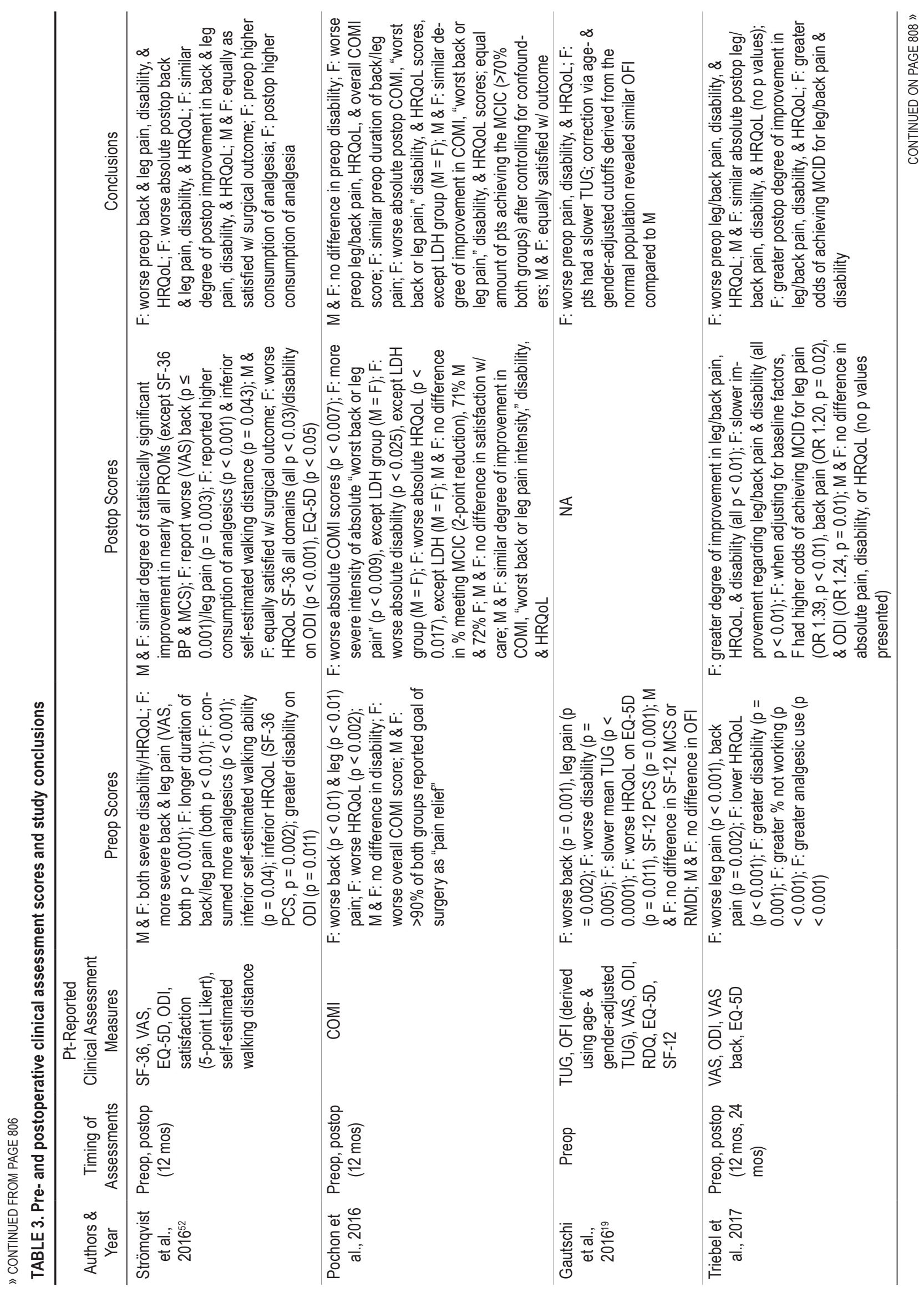




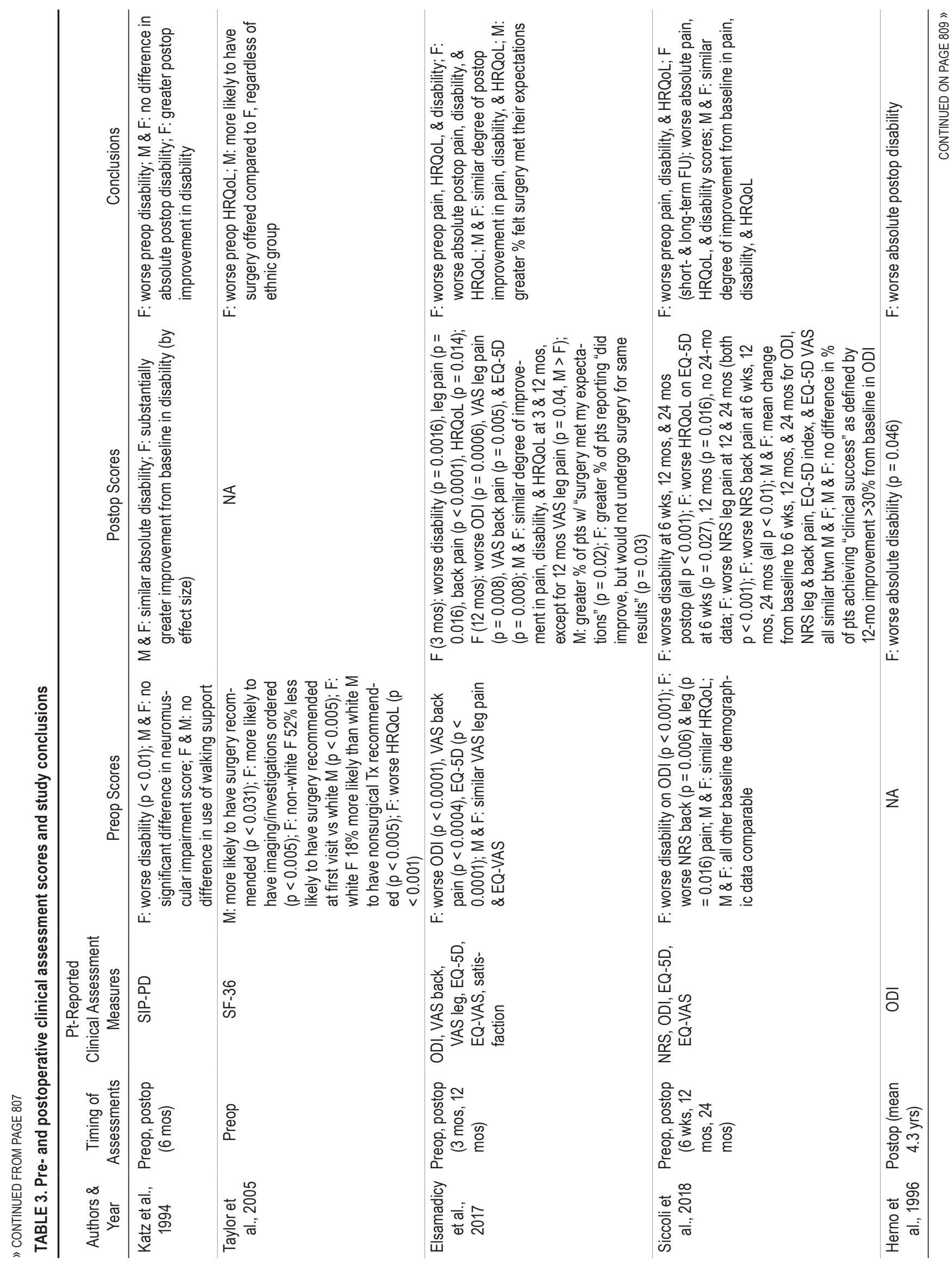




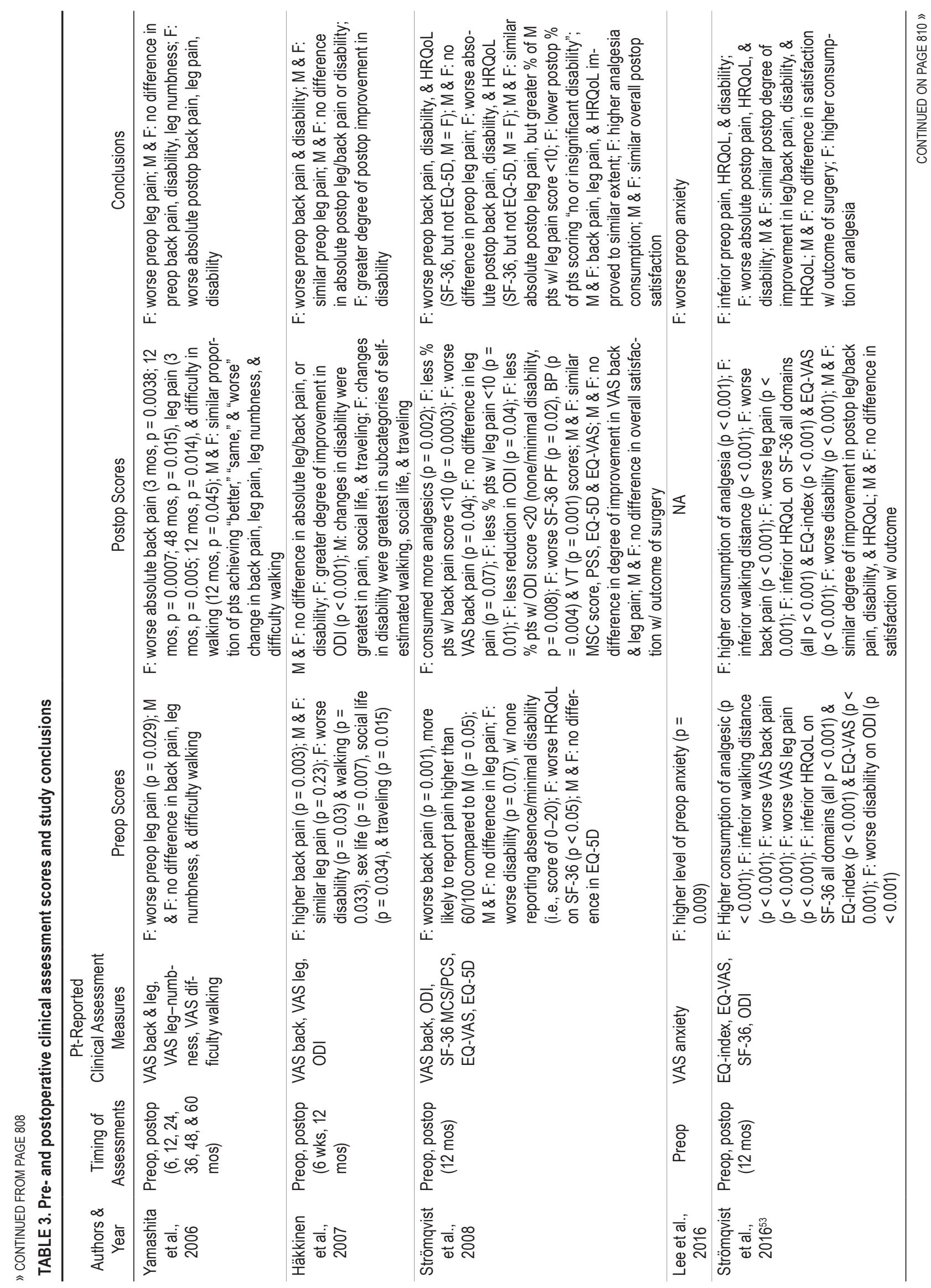




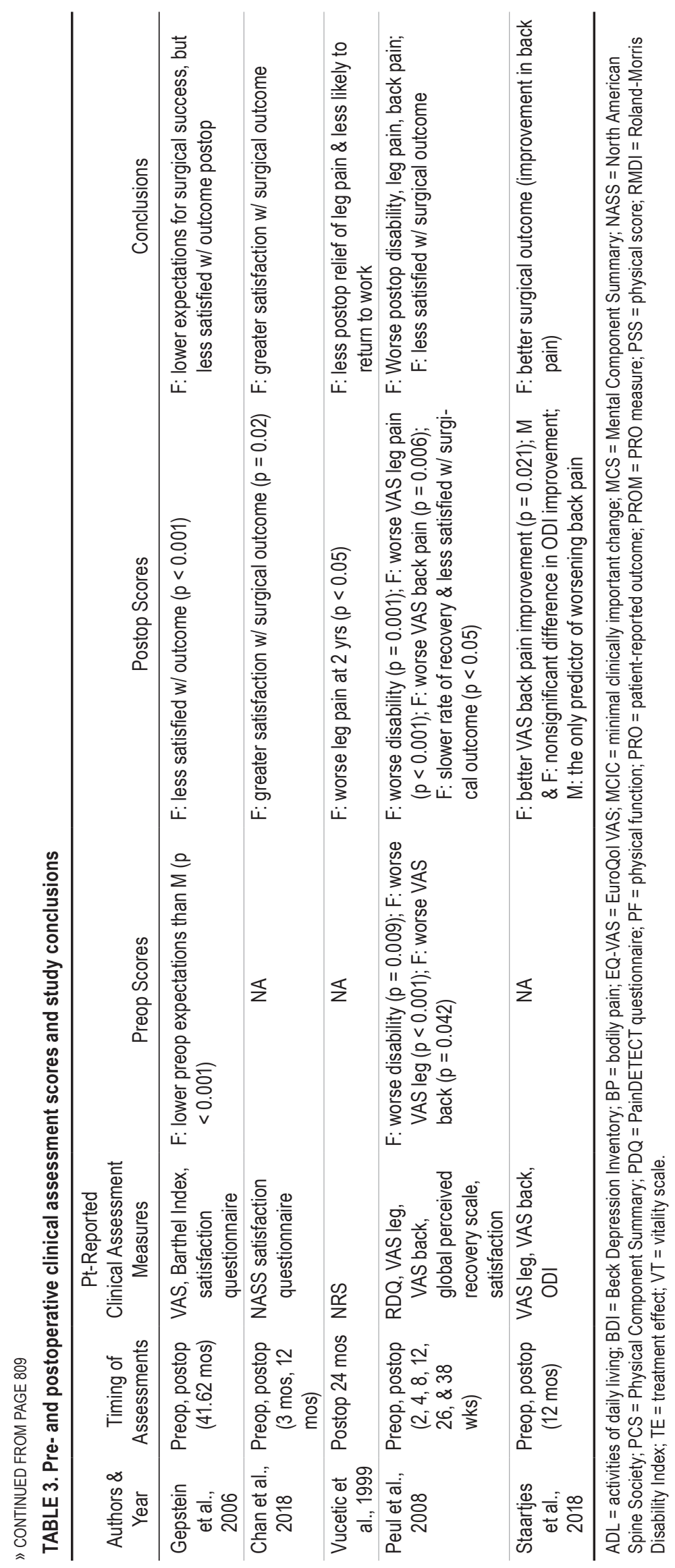




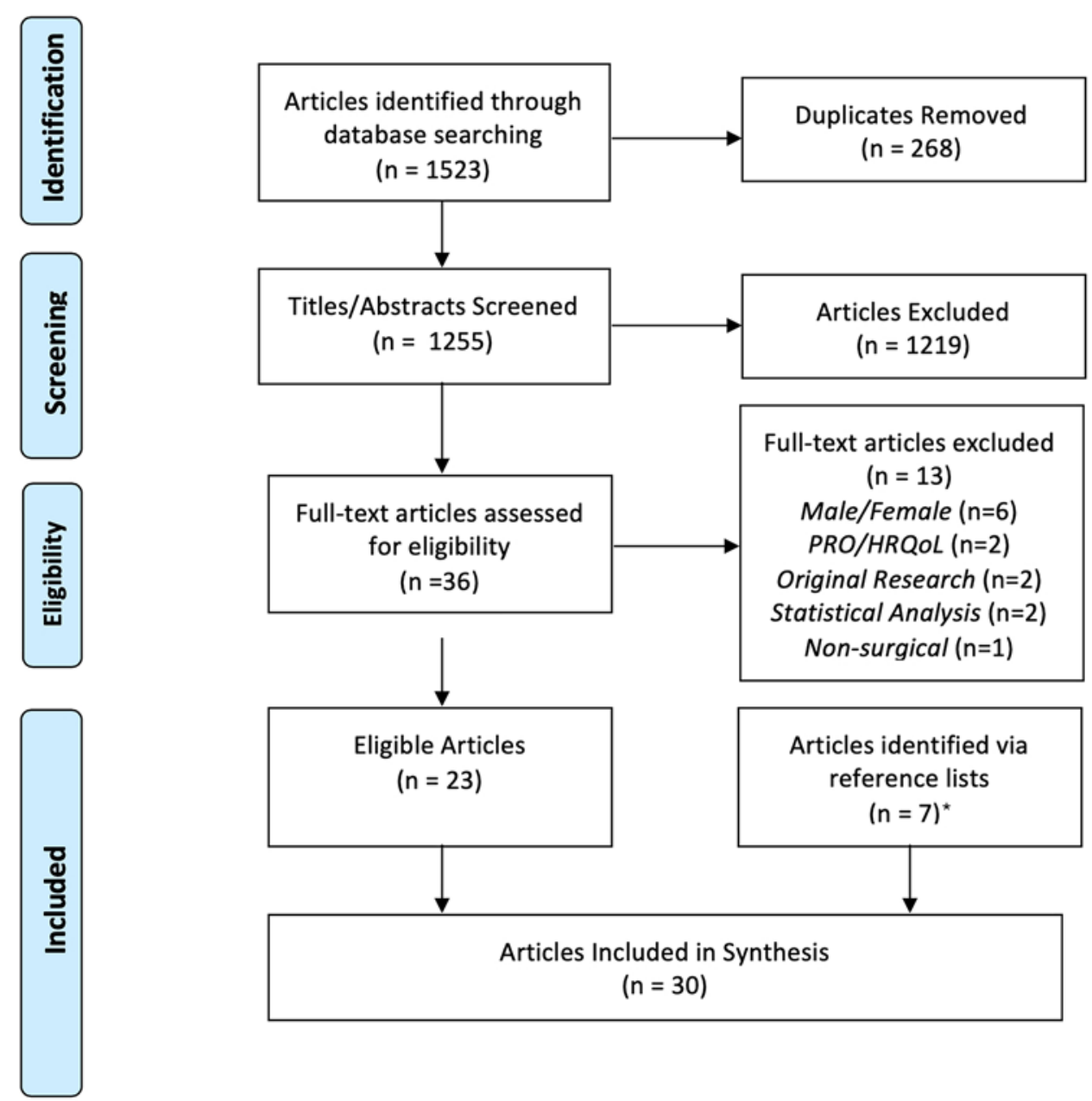

FIG. 1. Flowchart outlining the systematic scoping review process. *Additional articles identified and included by manually searching the reference list of the included full-text articles. Figure is available in color online only.

or HRQoL. Of the 15 studies reporting preoperative back or leg pain, mean pain intensity was significantly worse for females in 14 studies (93.3\%). A single study (6.7\%) reported no gender difference in pain but found worse preoperative disability among females ${ }^{57}$ No studies reported worse preoperative pain among males. Of the 16 studies reporting data on preoperative disability, $13(81.3 \%)$ found worse scores among females, whereas a single study (6.3\%) found worse scores among males, ${ }^{59}$ and $2(12.5 \%)$ found equivalent scores. ${ }^{41,58}$ Preoperative HRQoL data were reported in 12 studies. Females had worse scores compared to males in 9 studies (75.0\%), compared to equivalent scores in 3 studies $(25.0 \%) .48,58,59$ No studies found worse preoperative HRQoL among males.

\section{Preoperative Anxiety}

Preoperative anxiety was the focus of a single retrospective study including 150 patients. ${ }^{34}$ Anxiety was more prevalent among female patients.

\section{Postoperative Pain, Disability, and HRQoL}

Statistically significant gender differences in postop- erative patient-reported clinical assessment scores were identified for pain, disability, and HRQoL (Table 3). Twenty-five (83\%) of 30 studies reported at least one of the following categories: pain, disability, or HRQoL. Ten (40\%) reported only absolute scores, 5 (20\%) reported interval change or treatment effect, and $10(40 \%)$ reported both absolute scores and interval change. Most studies reported at least 12 months of follow-up data.

Of the 20 studies reporting absolute scores, $16(80 \%)$ found that females had worse scores in at least one outcome category. No study found males to have worse postoperative pain, disability, or HRQoL. Sixteen studies reported absolute pain scores. Females reported worse pain in 11 studies $(68.8 \%)$. Five (31.3\%) did not identify a difference between genders. Nineteen studies reported absolute postoperative disability scores. In 15 studies (78.9\%) females reported worse postoperative disability. Four (21.1\%) did not identify a difference between genders. Eight studies reported absolute postoperative HRQoL scores; females reported worse postoperative HRQoL in 6 studies $(75.0 \%), 14,41,48,50,52,53$ whereas 2 studies $(25.0 \%)$ found no gender differences. ${ }^{20,59}$ Global functional status was assessed using the Beaujon scoring system in a single 
study. ${ }^{37}$ The authors found worse scores for females at the 24-month follow-up.

Fifteen studies reported either interval change or treatment effect following surgery. Six studies (40\%) reported a similar interval change between genders for pain, disability, and HRQoL. 14,20,41,48,52,53 Five studies (33.3\%) reported that females fer, $29,39,49,56$ and 4 (26.7\%) found that males ${ }^{32,50,59,60}$ reported greater improvement, respectively. Of the 10 studies reporting postoperative interval change in pain, $7(70.0 \%)$ found no gender difference, ${ }^{14,20,41,48,50,52,53}$ and $1(10.0 \%)$ found that males ${ }^{60}$ and $2(20.0 \%)$ found that females ${ }^{49,56}$ reported a greater degree of improvement, respectively. Of the 13 studies reporting postoperative interval change in disability, $7(53.8 \%)$ found no gender difference, ${ }^{14,20,41,48,49,52,53}$ and $2(15.4 \%)$ found that males ${ }^{50,59}$ and $4(30.8 \%)$ found that females ${ }^{23,29,39,56}$ reported a greater degree of improvement, respectively. Ten studies reported an interval change in HRQoL: $8(80 \%)$ found no gender difference in interval change, ${ }^{14,20,41,48,50,52,53,59}$ whereas males reported greater improvement in a single study, ${ }^{32}$ and females in another. ${ }^{56}$

As aforementioned, 6 of 30 studies accounted for 27,754 patients $(84.2 \%)$. Four of the 6 studies, accounting for 17,284 patients, reported postoperative assessment scores. ${ }^{41,48,52,53}$ All 4 reported that female patients had worse absolute scores but similar interval change in preand postoperative pain, disability, and HRQoL. One study reported worse preoperative scores but did not report $\mathrm{ab}$ solute postoperative scores; these investigators reported a greater degree of postoperative improvement for females in pain, disability, and HRQoL.56 One study reported worse preoperative HRQLL among females but did not report postoperative data. ${ }^{54}$

\section{Preoperative Duration of Symptoms and Clinical Assessment Scores}

The majority of studies $(63.3 \%)$ did not report preoperative duration of symptoms. Duration was reported in 7 studies $(23.3 \%))^{12,23,37,40,41,47,52} 5(16.7 \%)$ reported no difference between genders, ${ }^{12,23,40,41,47}$ and $4(13.3 \%)$ reported data without statistical significance. ${ }^{26,53,58,59}$ All 5 studies reporting an equivalent preoperative duration of symptoms between genders reported inferior absolute clinical assessment scores among females, ${ }^{12,23,40,41,47} 4$ reported females had worse absolute postoperative clinical assessment scores,,$^{12,40,41,47}$ and 2 reported females had a greater degree of postoperative improvement..$^{23,41}$

\section{Postoperative Satisfaction With Surgical Outcome}

Postoperative patient satisfaction data were available for 10 studies $(33.3 \%)$. Five $(50.0 \%)$ found no gender difference in satisfaction with surgical outcome. , $^{6,50,52,53}$ Four studies $(40.0 \%)$ found that females are less satisfied, ${ }^{14,21,40,47}$ while a single study $(10.0 \%)$ found that males are less satisfied with surgical outcome. Three of the studies reporting equal satisfaction between males and females were published by the same research group. ${ }^{50,52,53}$ In all of the studies in which females reported less satisfaction with the surgical outcome, they also reported worse absolute pain score compared to males. In the single study reporting less satisfaction among males, no pain, disability, or HRQoL data were available.

\section{Pre- and Postoperative Analgesia Usage}

Four of 30 studies reported preoperative analgesia usage. ${ }^{47,52,53,56}$ A single study accounted for 11,237 patients. ${ }^{53}$ All 4 studies reported that female patients had greater preoperative analgesic use. Four studies reported postoperative analgesia usage; all found higher usage among females. ${ }^{47,50,52,53}$ Three of those studies reported equal postoperative satisfaction between genders. ${ }^{50,52,53}$

\section{Objective Scoring Measures}

A single study examined "pain thresholds" using quantitative sensory testing (QST). ${ }^{58}$ The authors reported prospective data on pre- and postoperative pain thresholds for heat and pressure among patients treated for disc herniation. Females had lower heat pain and pressure pain thresholds. Postoperatively, females had lower pressure pain and mechanical detection thresholds, whereas males reported a lower vibration detection threshold and mechanical pain sensitivity. Notably, there were no gender differences in postoperative patient-reported clinical assessment scores. Two studies from the same group utilized Timed-Up-and-Go (TUG) testing. The first reported no gender differences in preoperative TUG or Objective Functional Impairment (OFI) scores (derived using ageand gender-adjusted cutoff values for TUG scores). ${ }^{20} \mathrm{~A}$ similar interval change in postoperative scores was noted for males and females. The other study reported only preoperative data, with slower mean TUG among females and no difference in OFI. ${ }^{19}$

\section{Evidence Appraisal}

The majority of studies constitute level 4 evidence. .,7,12, $^{\text {, }}$ 14,19,26,29,32,37,47-49,56-59,63 The remainder constitute level $1 b,{ }^{40}$ $2 \mathrm{~b}, 2,20,21,23,34,39,41,50,52,53,60$ and $3 b^{54}$ evidence.

\section{Discussion}

This study summarizes the adult surgical literature regarding gender differences in patients with lumbar degenerative disease (disc degeneration, disc herniation, spondylolisthesis, and spinal canal stenosis). The data suggest that despite equal or greater postoperative improvement, females undergo surgery with inferior clinical status (pain, disability, HRQoL), leading to inferior postoperative clinical status. All studies reporting preoperative scores identified gender differences. Most studies reported worse preoperative pain $(93.3 \%)$, disability $(81.3 \%)$, and HRQoL (75\%) among females. The remainder reported equivalent results between males and females. Eighty percent of studies found that females had worse absolute postoperative scores in at least one category of pain, disability, or HRQoL, whereas $73.3 \%$ reported either an equivalent or greater degree of improvement between genders. No study found males to have worse absolute postoperative pain, disability, or HRQoL scores. A subgroup analysis of studies including only patients with disc herniation or spinal canal stenosis was performed (Supplemental Digital Content C). Trends in pre- and postoperative clinical assessment scores were similar to those identified for aggregate data from all studies. The majority of studies constitute level 4 evidence. 


\section{Patient Selection and Management Guidelines}

White males are reported to receive better access to interventions compared to females and minorities; examples include admission to an intensive care unit, access to lipid-lowering medication following myocardial infarction, cardiac catherization, renal dialysis, transplantation, and TJA. ${ }^{39,13,18,25,31,46}$ Perception of the risk and benefits of therapeutic interventions systematically varies across racial and gender groups, often reflecting the outcomes of care provided to those groups. ${ }^{28}$ Provider-level factors may also influence patient expectations, which patients access surgery, and satisfaction with clinical outcome..$^{38,50,51}$ Physicians often utilize evidence-based guidelines outlining the management of chronic conditions, which typically do not stratify by gender. ${ }^{1}$ This is likely related to a paucity of literature on gender differences in pre- and postoperative clinical assessment scores. Future research may facilitate guideline development with attention toward gender stratification. This has been exemplified by studies of carotid endarterectomy for the treatment of carotid stenosis. ${ }^{44}$

\section{Objective and Subjective Outcome Measurement}

The use of patient-reported clinical assessment scores in the context of patient-centered care is intuitive. Geography and culture may influence patient-reported assessment scores, as evidenced by varying conclusions regarding the management of lumbar degenerative conditions in randomized controlled trials (RCTs) from Europe and North America. ${ }^{17,22}$ Furthermore, patient-reported clinical assessment tools typically lack age and gender specificity; age- and gender-adjusted cutoff values are not readily available, as they are for objective TUG testing. ${ }^{19,38}$ We identified two studies that reported age- and genderadjusted cutoff values for TUG testing. ${ }^{19,20}$ One reported no gender difference in preoperative TUG scores adjusted for age- and gender-based cutoff values. ${ }^{20}$ No gender differences were observed for postoperative scores. The other reported only preoperative data, with slower mean TUG among females, but no difference in adjusted values. ${ }^{19}$ Time constraints during clinics may be prohibitive with respect to such testing.

Biological, environmental, and socioeconomic factors may influence gender role expectations of pain thresholds; both males and females report that females are more sensitive to, and less enduring of, pain. ${ }^{43}$ QST of patients undergoing lumbar surgery has revealed lower preoperative thresholds for both heat- and pressure-related pain among females. ${ }^{58}$ Postoperatively, females had lower pressure pain and mechanical detection thresholds, whereas males reported lower vibration detection threshold and mechanical pain sensitivity. Notably, there were no differences in patient-reported assessment scores.

\section{Gender Disparity in Joint Arthroplasty for the Treatment of Osteoarthritis}

Gender, racial, and geographic variability in the utilization of surgical therapy has been exemplified by studies of TJA for the treatment of osteoarthritis (OA). ${ }^{38}$ Hawker et al. demonstrated that females have a higher prevalence of OA compared to males, with worse pain and disability. ${ }^{25}$ No gender differences were observed in willingness to undergo hip and knee TJA; however, surgeons were less willing to offer TJA to females. In practice, the observed underuse of TJA in appropriate candidates is three times greater among females. ${ }^{62}$ Opinion surveys have found that $93 \%$ of surveyed orthopedic surgeons reported gender did not affect their decision to offer TJA. ${ }^{10,62}$ Borkhoff et al. conducted a blinded assessment of family physicians and orthopedic surgeons, examining standardized patients with OA of the knee, differing only by gender. ${ }^{5}$ Forty-two percent of physicians recommended TJA to the male but not the female patient. Eight percent of physicians recommended TJA to the female but not the male. Orthopedic surgeons were 22 times more likely, and family physicians 2 times more likely, to offer TJA to a male patient. The data suggest females are offered surgery with inferior clinical status but demonstrate equal or greater postoperative improvement compared to males. Further research should attempt to determine if this observation reflects a bias against offering surgery to female patients.

\section{Gender Differences in the Workup and Management of Lumbar Degenerative Disease}

It has been suggested that female patients present or are referred for assessment later in the course of their disease, leading to inferior clinical status at the time of surgery. ${ }^{41,48,56}$ The data herein support the claim regarding inferior clinical status among female patients at the time of surgery. Few studies have examined the impact of gender bias on workup and decision-making for the management of degenerative spinal conditions. ${ }^{54}$ It is unclear to what extent referral, patient selection, and patient preference contribute. Five of 7 studies examining preoperative duration of symptoms reported no difference between genders. ${ }^{12,23,40,41,47}$ All 5 studies reported that females had inferior clinical assessment scores. These findings suggest that duration of symptoms alone does not explain gender differences in clinical assessment scores.

A retrospective analysis of 5690 patients, attending an initial preoperative surgical assessment for degenerative lumbar disease, stratified the findings by gender. ${ }^{54} \mathrm{Al}-$ though females were more likely than males to have imaging tests ordered, males were more likely to be offered surgery. The number of patients referred for assessment or offered surgery at a later follow-up visit is not reported.

Kim et al. used a preference-based shared decisionmaking model to evaluate patient willingness to choose surgery or conservative management; male gender was associated with patient preference for surgery. ${ }^{30}$ Bono et al. found that preoperative back pain intensity was positively associated with patient acceptance of lumbar fusion complication risk, whereas gender was not. ${ }^{4}$ It has been reported that physicians believe female patients are more likely to experience adverse outcomes following TJA ${ }^{61}$ However, a systematic review found that males were at increased odds of death, but not complications, following spine surgery ${ }^{45}$ To our knowledge, no comparable study to that of Borkhoff et al. ${ }^{5}$ has prospectively examined surgeon willingness to offer spine surgery to standardized patients who only differ in gender. Prospective studies accounting for patient referral may facilitate identification of biases in patient selection for surgery. Gender of the surgeon may play 
a role. In this paper, only a single study reported surgeon gender, and indicated that all were male. ${ }^{50}$

\section{Gender Disparity in Lumbar Spine Surgery for Degenerative Conditions}

Pearson et al. reviewed Spine Outcomes Research Trial (SPORT) data for 607 patients by combining RCT and observational cohort study data for degenerative spondylolisthesis (DSL) via an as-treated analysis. ${ }^{39}$ Female gender was associated with greater treatment effect. Strömqvist et al. published data for 15,631 patients from the Swedish National Register for Spine Surgery, reporting that females scheduled for discectomy reported inferior walking ability, consumed more analgesics, and reported worse pain, disability, and HRQoL.51 A prospective cohort study of 4780 patients receiving fusion for lumbar degenerative disease found that females had inferior preoperative pain, disability, and $\mathrm{HRQoL}$, but greater postoperative improvement than males. ${ }^{56}$ Several studies report comparable findings; females report inferior clinical status, but similar postoperative improvement following treatment of lumbar disc herniation (LDH), spondylolisthesis, and spinal canal stenosis. ${ }^{23,33,41,52,53}$ Four studies found that males reported greater clinical improvement following surgery; males were more satisfied that surgery met their expectations, and females were more likely to report they would not undergo surgery for the same results..$^{32,50,59,60}$

\section{Sarcopenia, Frailty, and Severity of Radiographic Disease}

Sarcopenia has been investigated as a surrogate marker of frailty in patients undergoing spine surgery. ${ }^{65}$ Zakaria et al. found that the psoas area predicted postoperative complications in males but not females. ${ }^{65}$ Their results are not generalizable given the heterogeneous cohort that included deformity, revisions, and anterior procedures. A separate ambispective study of patients undergoing scheduled surgery for degenerative spine disease found that gender and BMI were associated with psoas size but not frailty. ${ }^{8}$ Psoas size did not predict the occurrence of adverse events, length of stay, or mortality. A study of 53,145 patients undergoing lumbar surgery for degenerative conditions found that only $4 \%$ are frail. ${ }^{16}$ Frailty was twice as common in patients greater than 65 years of age, although the mean age of their cohort was 56.1 years. They included patients with cervical and thoracic disease and these patients had higher rates of frailty compared to those with lumbar disease.

Frailty likely does not explain the gender differences identified in this review. First, the average age of patients in this study was approximately 50 years and there is a low prevalence of frailty in patients undergoing degenerative spine surgery, even among those over the age of 65 years. ${ }^{16}$ Second, sarcopenia does not correlate with frailty or postoperative outcomes. ${ }^{8}$

\section{Limitations}

Our review has several limitations. First, innumerable studies have examined the surgical treatment of lumbar degenerative disease without dichotomizing by gender. As such, a true systematic review was not feasible. Second, we did not search "gray literature." The majority of eligible studies were retrospective analyses of prospectively collected cohort data. The largest eligible study reported data from a nonconsecutive prospective database.$^{53}$ Only two RCTs were included, contributing $2.7 \%$ of the total patients. Many included studies had a small sample size and may be underpowered to detect meaningful clinical response to surgery. Most studies did not compare postoperative results to minimal clinically important difference (MCID) values. A small number of studies account for the majority of patients and were mostly published by European groups; cultural differences in patient-reported clinical assessment scores may vary geographically. The clinical assessment tools used to determine the severity of disease and response to treatment are, for the most part, subjective patient-reported measures. While validated, the relative contribution and importance of biology, pathology, and psychosocial considerations are not able to be determined. We did not set an inclusion limit on study publication year. While older studies preceding the development of novel surgical techniques may report inferior results, the majority of patients received routine discectomy or laminectomy. None of the included studies predate 1994. Lastly, we utilized a binary assessment of gender. To our knowledge, a nonbinary assessment has not been published in the spine surgery outcome literature.

\section{Conclusions}

Female patients undergoing surgery for lumbar degenerative disease (disc degeneration, disc herniation, spondylolisthesis, spinal canal stenosis) report worse preoperative pain, disability, and HRQoL. Following surgery, females report worse absolute pain, disability, and HRQoL, but demonstrate an equal or greater interval change compared to males.

\section{Acknowledgments}

We thank Robin Parker for assistance with development of the search strategy.

\section{References}

1. Airaksinen O, Brox JI, Cedraschi C, Hildebrandt J, KlaberMoffett J, Kovacs F, et al: Chapter 4. European guidelines for the management of chronic nonspecific low back pain. Eur Spine J 15 (Suppl 2):S192-S300, 2006

2. Airaksinen O, Herno A, Turunen V, Saari T, Suomlainen O: Surgical outcome of 438 patients treated surgically for lumbar spinal stenosis. Spine (Phila Pa 1976) 22:2278-2282, 1997

3. Bloembergen WE, Mauger EA, Wolfe RA, Port FK: Association of gender and access to cadaveric renal transplantation. Am J Kidney Dis 30:733-738, 1997

4. Bono CM, Harris MB, Warholic N, Katz JN, Carreras E, White A, et al: Pain intensity and patients' acceptance of surgical complication risks with lumbar fusion. Spine (Phila Pa 1976) 38:140-147, 2013

5. Borkhoff CM, Hawker GA, Kreder HJ, Glazier RH, Mahomed NN, Wright JG: The effect of patients' sex on physicians' recommendations for total knee arthroplasty. CMAJ 178:681-687, 2008

6. Bouras T, Stranjalis G, Loufardaki M, Sourtzis I, Stavrinou LC, Sakas DE: Predictors of long-term outcome in an elderly group after laminectomy for lumbar stenosis. J Neurosurg Spine 13:329-334, 2010

7. Chan AK, Bisson EF, Bydon M, Glassman SD, Foley KT, 
Potts EA, et al: Women fare best following surgery for degenerative lumbar spondylolisthesis: a comparison of the most and least satisfied patients utilizing data from the Quality Outcomes Database. Neurosurg Focus 44(1):E3, 2018

8. Charest-Morin R, Street J, Zhang H, Roughead T, Ailon T, Boyd M, et al: Frailty and sarcopenia do not predict adverse events in an elderly population undergoing non-complex primary elective surgery for degenerative conditions of the lumbar spine. Spine J 18:245-254, 2018

9. Chibnall JT, Tait RC, Andresen EM, Hadler NM: Race differences in diagnosis and surgery for occupational low back injuries. Spine (Phila Pa 1976) 31:1272-1275, 2006

10. Coyte PC, Hawker G, Croxford R, Attard C, Wright JG: Variation in rheumatologists' and family physicians' perceptions of the indications for and outcomes of knee replacement surgery. J Rheumatol 23:730-738, 1996

11. Dalury DF, Mason JB, Murphy JA, Adams MJ: Analysis of the outcome in male and female patients using a unisex total knee replacement system. J Bone Joint Surg Br 91:357-360, 2009

12. Dedering A, Harms-Ringdahl K, Nèmeth G: Back extensor muscle fatigue in patients with lumbar disc herniation. Preoperative and post-operative analysis of electromyography, endurance time and subjective factors. Eur Spine J 15:559569,2006

13. Di Cecco R, Patel U, Upshur REG: Is there a clinically significant gender bias in post-myocardial infarction pharmacological management in the older $(>60)$ population of a primary care practice? BMC Fam Pract 3:8, 2002

14. Elsamadicy AA, Reddy GB, Nayar G, Sergesketter A, Zakare-Fagbamila R, Karikari IO, et al: Impact of gender disparities on short-term and long-term patient reported outcomes and satisfaction measures after elective lumbar spine surgery: a single institutional study of 384 patients. World Neurosurg 107:952-958, 2017

15. Fillingim RB, King CD, Ribeiro-Dasilva MC, Rahim-Williams B, Riley JL III: Sex, gender, and pain: a review of recent clinical and experimental findings. J Pain 10:447-485, 2009

16. Flexman AM, Charest-Morin R, Stobart L, Street J, Ryerson CJ: Frailty and postoperative outcomes in patients undergoing surgery for degenerative spine disease. Spine J 16:13151323,2016

17. Försth P, Ólafsson G, Carlsson T, Frost A, Borgström F, Fritzell P, et al: A randomized, controlled trial of fusion surgery for lumbar spinal stenosis. N Engl J Med 374:1413-1423, 2016

18. Fowler RA, Sabur N, Li P, Juurlink DN, Pinto R, Hladunewich MA, et al: Sex-and age-based differences in the delivery and outcomes of critical care. CMAJ 177:1513-1519, 2007

19. Gautschi OP, Corniola MV, Smoll NR, Joswig H, Schaller K, Hildebrandt G, et al: Sex differences in subjective and objective measures of pain, functional impairment, and healthrelated quality of life in patients with lumbar degenerative disc disease. Pain 157:1065-1071, 2016

20. Gautschi OP, Smoll NR, Corniola MV, Joswig H, Schaller K, Hildebrandt G, et al: Sex differences in lumbar degenerative disc disease. Clin Neurol Neurosurg 145:52-57, 2016

21. Gepstein R, Arinzon Z, Adunsky A, Folman Y: Decompression surgery for lumbar spinal stenosis in the elderly: preoperative expectations and postoperative satisfaction. Spinal Cord 44:427-431, 2006

22. Ghogawala Z, Dziura J, Butler WE, Dai F, Terrin N, Magge $\mathrm{SN}$, et al: Laminectomy plus fusion versus laminectomy alone for lumbar spondylolisthesis. N Engl J Med 374:14241434,2016

23. Häkkinen A, Kautiainen H, Järvenpää S, Arkela-Kautiainen $\mathrm{M}$, Ylinen J: Changes in the total Oswestry Index and its ten items in females and males pre- and post-surgery for lumbar disc herniation: a 1-year follow-up. Eur Spine J 16:347-352, 2007

24. Hall DE, Prochazka AV, Fink AS: Informed consent for clinical treatment. CMAJ 184:533-540, 2012

25. Hawker GA, Wright JG, Coyte PC, Williams JI, Harvey B, Glazier R, et al: Differences between men and women in the rate of use of hip and knee arthroplasty. N Engl J Med 342:1016-1022, 2000

26. Herno A, Airaksinen O, Saari T, Svomalainen O: Pre- and postoperative factors associated with return to work following surgery for lumbar spinal stenosis. Am J Ind Med 30:473-478, 1996

27. Howick J, Chalmers I, Glasziou P, Greenhalgh T, Heneghan C, Liberati A, et al: The Oxford Levels of Evidence 2. Oxford: Oxford Centre for Evidence-Based Medicine, 2009 (https://www.cebm.net/index.aspx?o=5653) [Accessed December 5, 2019]

28. Katz JN: Patient preferences and health disparities. JAMA 286:1506-1509, 2001

29. Katz JN, Wright EA, Guadagnoli E, Liang MH, Karlson EW, Cleary PD: Differences between men and women undergoing major orthopedic surgery for degenerative arthritis. Arthritis Rheum 37:687-694, 1994

30. Kim HJ, Park JY, Kang KT, Chang BS, Lee CK, Yeom JS: Factors influencing the surgical decision for the treatment of degenerative lumbar stenosis in a preference-based shared decision-making process. Eur Spine J 24:339-347, 2015

31. Kjellstrand CM, Logan GM: Racial, sexual and age inequalities in chronic dialysis. Nephron 45:257-263, 1987

32. Korovessis P, Repantis T, Papazisis Z, Iliopoulos P: Effect of sagittal spinal balance, levels of posterior instrumentation, and length of follow-up on low back pain in patients undergoing posterior decompression and instrumented fusion for degenerative lumbar spine disease: a multifactorial analysis. Spine (Phila Pa 1976) 35:898-905, 2010

33. Leboeuf-Yde C, Nielsen J, Kyvik KO, Fejer R, Hartvigsen J: Pain in the lumbar, thoracic or cervical regions: do age and gender matter? A population-based study of 34,902 Danish twins 20-71 years of age. BMC Musculoskelet Disord 10:39, 2009

34. Lee JS, Park YM, Ha KY, Cho SW, Bak GH, Kim KW: Preoperative anxiety about spinal surgery under general anesthesia. Eur Spine J 25:698-707, 2016

35. Lurie N: Health disparities-less talk, more action. New Engl J Med 353:727-729, 2005

36. Magone K, Kemker BP III, Pilipenko N, O’Connor E, Walter $\mathrm{N}$, Atkinson T: The new surgical technique for improving total knee and hip arthroplasty outcomes: patient selection. J Arthroplasty 32:2070-2076, 2017

37. Mariconda M, Zanforlino G, Celestino GA, Brancaleone S, Fava R, Milano C: Factors influencing the outcome of degenerative lumbar spinal stenosis. J Spinal Disord 13:131-137, 2000

38. Novicoff WM, Saleh KJ: Examining sex and gender disparities in total joint arthroplasty. Clin Orthop Relat Res 469:1824-1828, 2011

39. Pearson AM, Lurie JD, Tosteson TD, Zhao W, Abdu WA, Weinstein JN: Who should undergo surgery for degenerative spondylolisthesis? Treatment effect predictors in SPORT. Spine (Phila Pa 1976) 38:1799-1811, 2013

40. Peul WC, Brand R, Thomeer RTWM, Koes BW: Influence of gender and other prognostic factors on outcome of sciatica. Pain 138:180-191, 2008

41. Pochon L, Kleinstück FS, Porchet F, Mannion AF: Influence of gender on patient-oriented outcomes in spine surgery. Eur Spine J 25:235-246, 2016

42. Ritter MA, Wing JT, Berend ME, Davis KE, Meding JB: The clinical effect of gender on outcome of total knee arthroplasty. J Arthroplasty 23:331-336, 2008 
43. Robinson ME, Riley JL III, Myers CD, Papas RK, Wise EA, Waxenberg LB, et al: Gender role expectations of pain: relationship to sex differences in pain. J Pain 2:251-257, 2001

44. Rothwell PM, Eliasziw M, Gutnikov SA, Warlow CP, Barnett HJM: Endarterectomy for symptomatic carotid stenosis in relation to clinical subgroups and timing of surgery. Lancet 363:915-924, 2004

45. Schoenfeld AJ, Reamer EN, Wynkoop EI, Choi H, Bono CM: Does patient sex affect the rate of mortality and complications after spine surgery? A systematic review. Clin Orthop Relat Res 473:2479-2486, 2015

46. Schulman KA, Berlin JA, Harless W, Kerner JF, Sistrunk S, Gersh BJ, et al: The effect of race and sex on physicians' recommendations for cardiac catheterization. N Engl J Med 340:618-626, 1999

47. Shabat S, Folman Y, Arinzon Z, Adunsky A, Catz A, Gepstein R: Gender differences as an influence on patients' satisfaction rates in spinal surgery of elderly patients. Eur Spine J 14:1027-1032, 2005

48. Siccoli A, Staartjes VE, de Wispelaere MP, Schröder ML: Gender differences in degenerative spine surgery: do female patients really fare worse? Eur Spine J 27:2427-2435, 2018

49. Staartjes VE, Vergroesen PA, Zeilstra DJ, Schröder ML: Identifying subsets of patients with single-level degenerative disc disease for lumbar fusion: the value of prognostic tests in surgical decision making. Spine J 18:558-566, 2018

50. Strömqvist F, Ahmad M, Hildingsson C, Jönsson B, Strömqvist B: Gender differences in lumbar disc herniation surgery. Acta Orthop 79:643-649, 2008

51. Strömqvist F, Strömqvist B, Jönsson B, Karlsson MK: Gender differences in patients scheduled for lumbar disc herniation surgery: a national register study including 15,631 operations. Eur Spine J 25:162-167, 2016

52. Strömqvist F, Strömqvist B, Jönsson B, Karlsson MK: Gender differences in the surgical treatment of lumbar disc herniation in elderly. Eur Spine J 25:3528-3535, 2016

53. Strömqvist F, Strömqvist B, Jönsson B, Karlsson MK: Inferior outcome of lumbar disc surgery in women due to inferior preoperative status: a prospective study in 11,237 patients. Spine (Phila Pa 1976) 41:1247-1252, 2016

54. Taylor BA, Casas-Ganem J, Vaccaro AR, Hilibrand AS, Hanscom BS, Albert TJ: Differences in the work-up and treatment of conditions associated with low back pain by patient gender and ethnic background. Spine (Phila Pa 1976) 30:359-364, 2005

55. Tricco AC, Lillie E, Zarin W, O'Brien KK, Colquhoun H, Levac D, et al: PRISMA Extension for Scoping Reviews (PRISMA-ScR): checklist and explanation. Ann Intern Med 169:467-473, 2018

56. Triebel J, Snellman G, Sandén B, Strömqvist F, Robinson Y: Women do not fare worse than men after lumbar fusion surgery: two-year follow-up results from 4,780 prospectively collected patients in the Swedish National Spine Register with lumbar degenerative disc disease and chronic low back pain. Spine J 17:656-662, 2017

57. Tropiano P, Huang RC, Girardi FP, Cammisa FP Jr, Marnay T: Lumbar total disc replacement. Seven to eleven-year follow-up. J Bone Joint Surg Am 87:490-496, 2005

58. Tschugg A, Löscher WN, Lener S, Wildauer M, Hartmann $S$, Neururer S, et al: Gender differences after lumbar sequestrectomy: a prospective clinical trial using quantitative sensory testing. Eur Spine J 26:857-864, 2017
59. Ungureanu G, Chitu A, Iancu I, Kakucs C, Maior T, Florian IS: Gender differences in the self-assessment of quality of life and disability after spinal fusion for chronic low back pain at a neurosurgical center in Eastern Europe. Neurospine 15:261-268, 2018

60. Vucetic N, Astrand P, Güntner P, Svensson O: Diagnosis and prognosis in lumbar disc herniation. Clin Orthop Relat Res (361):116-122, 1999

61. Whitlock KG, Piponov HI, Shah SH, Wang OJ, Gonzalez $\mathrm{MH}$ : Gender role in total knee arthroplasty: a retrospective analysis of perioperative outcomes in US patients. J Arthroplasty 31:2736-2740, 2016

62. Wright JG, Coyte P, Hawker G, Bombardier C, Cooke D, Heck D, et al: Variation in orthopedic surgeons' perceptions of the indications for and outcomes of knee replacement. CMAJ 152:687-697, 1995

63. Yamashita K, Ohzono K, Hiroshima K: Five-year outcomes of surgical treatment for degenerative lumbar spinal stenosis: a prospective observational study of symptom severity at standard intervals after surgery. Spine (Phila Pa 1976) 31:1484-1490, 2006

64. Yavin D, Casha S, Wiebe S, Feasby TE, Clark C, Isaacs A, et al: Lumbar fusion for degenerative disease: a systematic review and meta-analysis. Neurosurgery 80:701-715, 2017

65. Zakaria HM, Schultz L, Mossa-Basha F, Griffith B, Chang $\mathrm{V}$ : Morphometrics as a predictor of perioperative morbidity after lumbar spine surgery. Neurosurg Focus 39(4):E5, 2015

\section{Disclosures}

The authors report no conflict of interest concerning the materials or methods used in this study or the findings specified in this paper.

\section{Author Contributions}

Conception and design: Pickett, MacLean. Acquisition of data: MacLean, Touchette, Han. Analysis and interpretation of data: MacLean, Touchette, Han. Drafting the article: MacLean, Touchette, Han, Christie. Critically revising the article: all authors. Reviewed submitted version of manuscript: all authors. Approved the final version of the manuscript on behalf of all authors: Pickett. Statistical analysis: MacLean, Touchette. Administrative/technical/material support: Pickett, Christie. Study supervision: Pickett, Christie.

\section{Supplemental Information \\ Online-Only Content}

Supplemental material is available with the online version of the article.

Supplemental Digital Content A-C. https://thejns.org/doi/ suppl/10.3171/2019.11.SPINE19896.

\section{Correspondence}

Gwynedd E. Pickett: Dalhousie University and Nova Scotia Health Authority, Halifax, NS, Canada.gepickett@dal.ca. 